\title{
Description and seasonal detection of two potential whale calls recorded in the Indian Ocean
}

\author{
Andreia G. Sousa ${ }^{a)}$ and Danielle Harris \\ Centre for Research into Ecological and Environmental Modelling, The Observatory, Buchanan Gardens, \\ University of St. Andrews, St. Andrews, Fife, KY16 9LZ, United Kingdom
}

(Received 17 November 2014; revised 26 June 2015; accepted 5 August 2015; published online 9 September 2015)

\begin{abstract}
Unidentified acoustic signals are recorded by hydrophones placed in the world's oceans. Some of these sounds are suspected to originate from marine mammals. In this study, two acoustic signals recorded by two arrays at Diego Garcia in the northern Indian Ocean are described. Data were available between January 2002 and December 2003. Signals were detected manually using long-term spectral average plots. Time and frequency measurements were taken from a sample of both signals. The first unidentified signal [Diego Garcia Downsweep (DGD)] consisted of two main components. The mean frequency range of the entire signal was $19.3-45.0 \mathrm{~Hz}$, with a mean duration of $36.5 \mathrm{~s}(n=22)$. Detections of DGD at the northern array peaked in the austral summer, though detections at the southern array peaked during winter and spring. The second unidentified signal [Diego Garcia Croak (DGC)] consisted of one component with a mean frequency range of $16.9-49.6 \mathrm{~Hz}$. The mean duration of the signal was $13.1 \mathrm{~s}(n=10)$. Detections of DGC did not follow a clear seasonal pattern. These signals followed characteristics of biological sources, suggesting that they could be whale calls. Fin whale calls and possible blue whales $D$-calls were also identified in the data. (C) 2015 Acoustical Society of America.
\end{abstract}

[http://dx.doi.org/10.1121/1.4928719]

Pages: $1379-1388$

\section{INTRODUCTION}

Traditionally, animal populations have been monitored visually by researchers, whether on land or at sea. However, there are obvious limits to this approach: visual surveys cannot take place easily at night or in bad weather conditions. Furthermore, some species are difficult to survey by sight due to their habitat or behavior. For example, many marine mammal species are notoriously challenging to survey, as they spend so little of their time at the sea surface.

Acoustic monitoring provides an alternative method with which to survey animals. In particular, passive acoustic monitoring (PAM), where sounds from the surrounding environment are simply recorded, is an unintrusive technique and has been used to study a wide range of animals, including species of fish, marine mammals, birds, primates, insects, and amphibians (e.g., Luczkovich et al., 2008; Celis-Murillo et al., 2009; Hu et al., 2009; Burton and Nietsch, 2010; Puissant and Sueur, 2010; Van Opzeeland et al., 2010). PAM has the potential to overcome some of the limitations of visual surveys, provided that the species of interest makes a sound that can be used as a cue to indicate that an individual is present. Passive acoustic surveys are less sensitive to weather conditions, can collect data around the clock, and equipment can be left in situ for extended time periods, enabling long term datasets to be collected throughout all seasons.

In particular, PAM has been used to monitor a wide range of cetacean species, from the smallest species such as the vaquita (Phocoena sinus) (e.g., Rojas-Bracho et al., 2010) to the largest-the blue whale (Balaenoptera

\footnotetext{
${ }^{\text {a)} E l e c t r o n i c ~ m a i l: ~ a n d r e i a g s s @ g m a i l . c o m ~}$
}

musculus) (e.g., Stafford et al., 2011). PAM can be used in a wide range of research applications, from individual-level behavioral studies (e.g., feeding behavior; Tyack et al., 2006) to population level processes (e.g., distribution and movement patterns; Samaran et al., 2013).

In order for PAM to be an effective monitoring tool, the acoustic repertoire of a given species of interest has to be well understood. In the case of cetaceans, a diverse range of sounds are produced (reviewed in Au and Hastings, 2008), and the complexity and breadth of each species' vocal repertoire varies.

However, there are well documented sounds suspected to be produced by marine mammals but that currently remain unidentified. For example, the "Watkin's whale" is a unique sound from an unknown source (Watkins et al., 2000; Watkins et al., 2004). It has been recorded in the North East Pacific and the Gulf of Alaska, and has some resemblance to a blue whale vocalization also recorded in the North East Pacific. It is suspected to come from a large whale, possibly a blue-fin whale hybrid (Watkins et al., 2004; Stafford et al., 2007). Other examples of unidentified sounds that are attributed to large whales are described in Stafford et al. (1999). In some cases, it has been possible to link unidentified signals with cetaceans. For example, as a result of a combined visual and passive acoustic survey, it was concluded that minke whales (Balaenoptera acutorostrata) were the source of a previously unidentified sound, known as the "boing" sound, recorded in the North Pacific Ocean (Rankin and Barlow, 2005). However, there are still many recorded unidentified acoustic signals that could be produced by cetaceans, suggesting that our knowledge of the collection of sounds produced by these animals is incomplete. 
In this study, we describe two unidentified acoustic signals, which were recorded at Diego Garcia, an island in the Chagos Archipelago in the northern Indian Ocean, an area known to support a wide range of cetacean species. Recordings from Diego Garcia have been used extensively in previous blue whale acoustic studies (Stafford et al., 2004; Stafford et al., 2011; Harris, 2012). Both unidentified acoustic signals in this study have been frequently opportunistically detected in the Diego Garcia dataset (Harris, 2012) but to date no formal description of these signals has been made. The Diego Garcia Downsweep (DGD) signal has been previously described by McDonald et al. (2006) as the Diego Garcia variant of the Madagascan call, though it has never been recorded in the presence of a whale. By describing such signals and making the data available to the wider scientific community, it is hoped that the source of these signals will be identified more quickly.

\section{METHODS}

\section{A. Study area}

We examined acoustic recordings from hydrophones at Diego Garcia, an island in the north-central Indian Ocean, located at approximately $7.4^{\circ} \mathrm{S}, 72.4^{\circ} \mathrm{E}$ (Fig. 1). The hydrophones are part of the International Monitoring System (IMS), established under the Comprehensive Nuclear Test Ban Treaty, and are designed to detect nuclear explosions. There are six hydrophones at Diego Garcia arranged in two separate arrays. Both arrays are triads, in triangular formations, with approximately $2.5 \mathrm{~km}$ between hydrophones (Hanson, 2001). One triad is situated north of Diego Garcia $\left(6.3^{\circ} \mathrm{S}, 71.0^{\circ} \mathrm{E}\right.$; here called Diego Garcia North or DGN) and the other is south of the island $\left(7.6^{\circ} \mathrm{S}, 72.5^{\circ} \mathrm{E}\right.$; here called Diego Garcia South or DGS) (Fig. 1). The two triads are approximately $220 \mathrm{~km}$ apart. The hydrophones are suspended in the Sound Fixing and Ranging (SOFAR) channel using sub-surface buoys and sea floor anchors [Preparatory Commission for the Comprehensive Nuclear-Test-Ban Treaty Organisation (CTBTO), 2010]. Data are relayed from the hydrophones via an underwater cable back to a landbased station. The hydrophones have a sampling rate of $250 \mathrm{~Hz}$ and a flat response between 20 and $100 \mathrm{~Hz}$.

\section{B. Data availability}

Data were available from all hydrophones at both sites between January 2002 and December 2003. There were

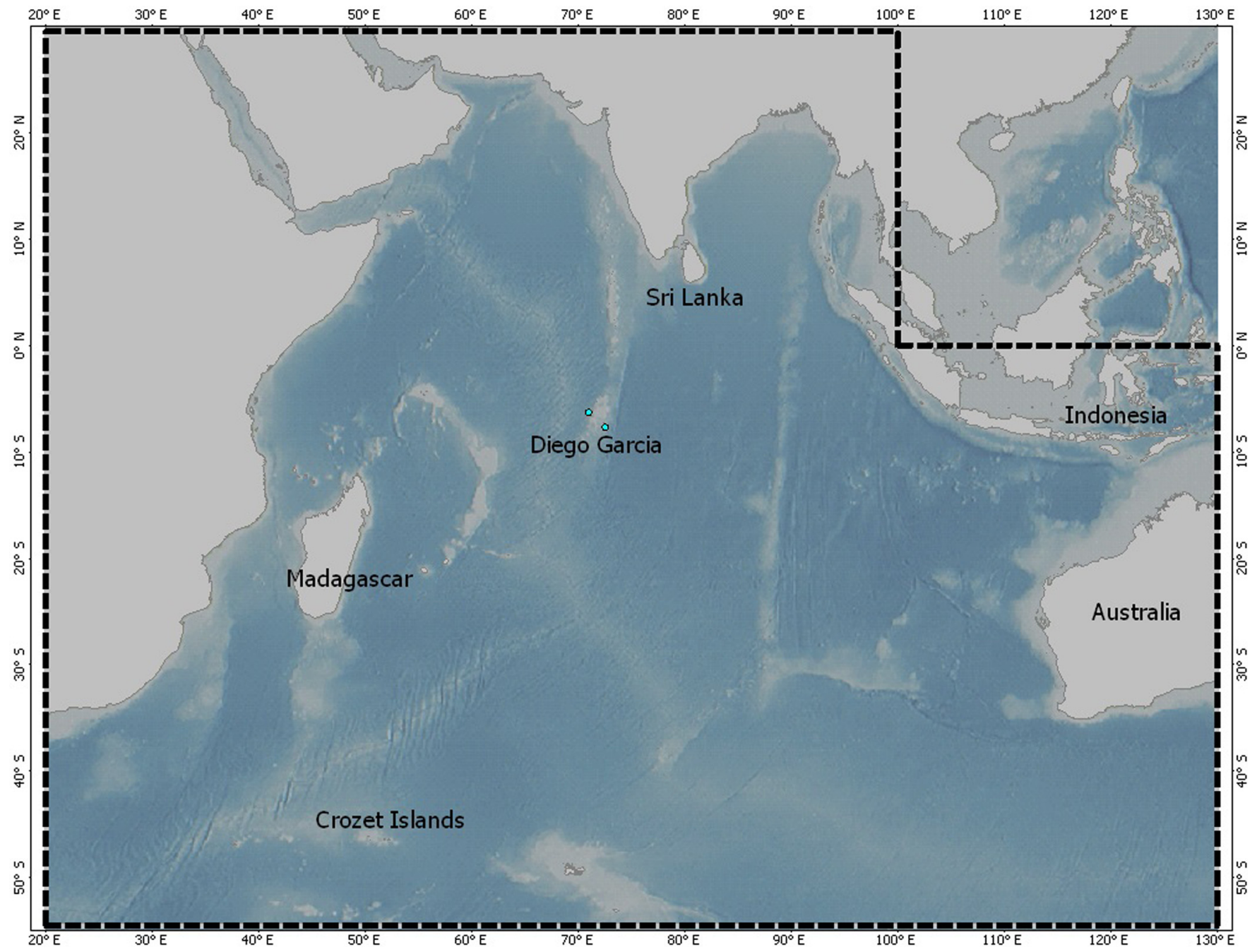

FIG. 1. (Color online) Map of the area of the IOS. The location of the Diego Garcia hydrophones (the northern triad and the southern triad) are denoted by the blue circles. 
some data gaps but, at both sites, each month had a minimum of 28 days with data, apart from January 2002 (DGN: 11 days; DGS: 2 days), July 2002 (DGS: 19 days), and December 2003 (DGN: 11 days; DGS: 27 days). In total there were 331 and 339 days of data available at DGN in 2002 and 2003, respectively, and 310 and 332 available days of data for DGS for the same years. The data were downloaded as binary files (32 bit floating point, big endian format) from the U.S. Army Space and Missile Defense Command Monitoring Research Program website. Audio.wav files were then created using MATLAB (Mathworks, 2012).

\section{Data analysis}

Data from one hydrophone (IMS identifier: H08N1) from DGN and another from DGS (H08S1) were visually analyzed. Data were only analyzed from one hydrophone at each site, since the close instrument spacing at each triad meant that recordings from one hydrophone were representative of all instruments in that triad. Long term spectral average (LTSA) plots were created from the .wav files and viewed using the MATLAB-based (Mathworks, 2012) software package Triton (Wiggins, 2003). LTSA plots are compressed spectrograms, where spectra are averaged over a defined amount of time ( $60 \mathrm{~s}$ in this study). This allows several hours of data to be viewed at once, enabling acoustic activity in the frequency range of interest to be easily visually detected. For each displayed LTSA, the entire frequency range was plotted $(0-125 \mathrm{~Hz})$ and the time axis was set to display $12 \mathrm{~h}$ of data. Brightness and contrast were adjusted to 8 and 200 (arbitrary units), respectively, to produce the best visual image. In addition, each viewing window was equalized to improve the signal-to-noise ratio. When a sound of interest was identified in the LTSA, the corresponding original spectrogram was displayed (also in Triton) so that the signal could be viewed in detail. The spectrogram parameters were defined as follows: display length: $360 \mathrm{~s}$, Hanning window, frame length: 512 samples, overlap: $80 \%$, equalized, brightness: -4 , contrast: 200 .

Whenever either signal of interest (named the DGD and Diego Garcia Croak, DGC) (Fig. 2) were detected in the dataset, the date and time of the detection was recorded. Since both signals could occur repetitively in bouts, the beginning and end time of each bout was recorded rather than the time of every signal.

A grading system was also developed to represent the quality of the acoustic signals. Signals were considered grade " 1 " when the signal-to-noise ratio was high enough so that energy could be clearly seen across the entire frequency range, grade " 2 " when the overall shape of the signal was clearly visible, though energy across the entire frequency range could not be distinguished, and grade " 3 " when the overall shape was not clear, though the signal was still identifiable. Signals in a bout could have a range of grades, which was also noted.

In order to select a number of signals for measurement, the following criteria were applied: (1) only grade 1 signals
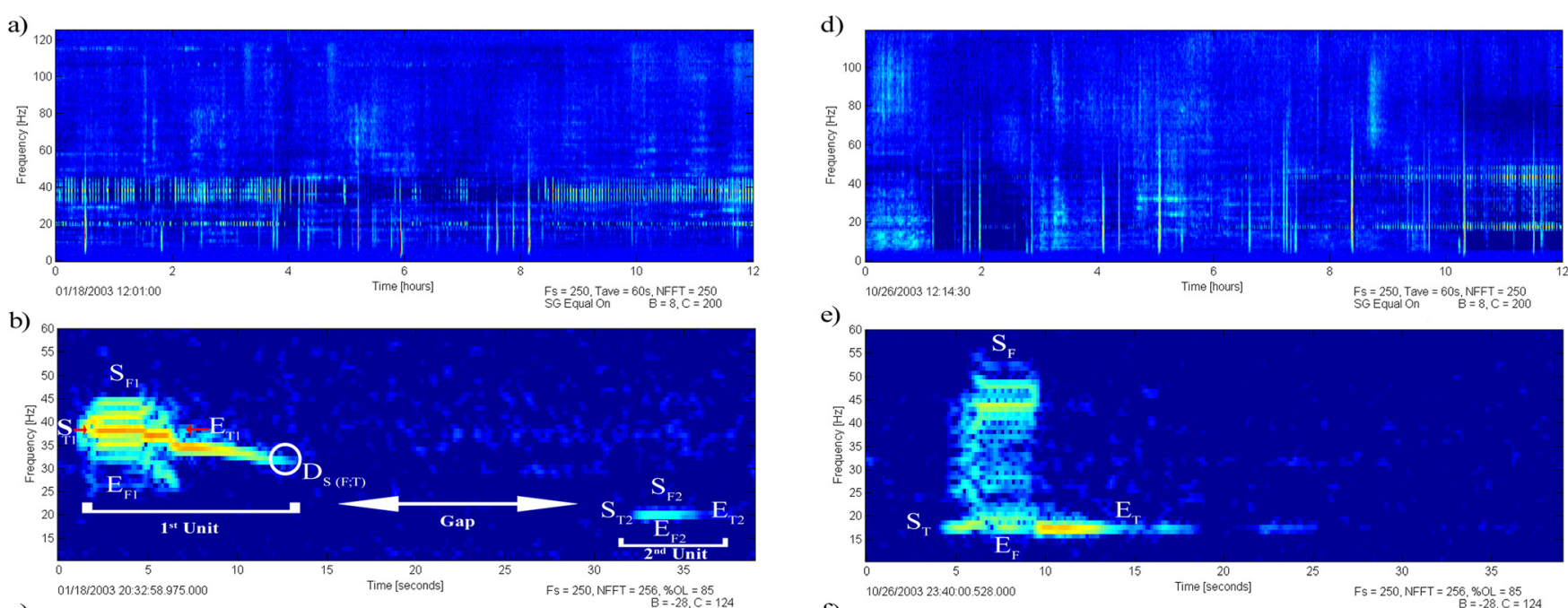

e)
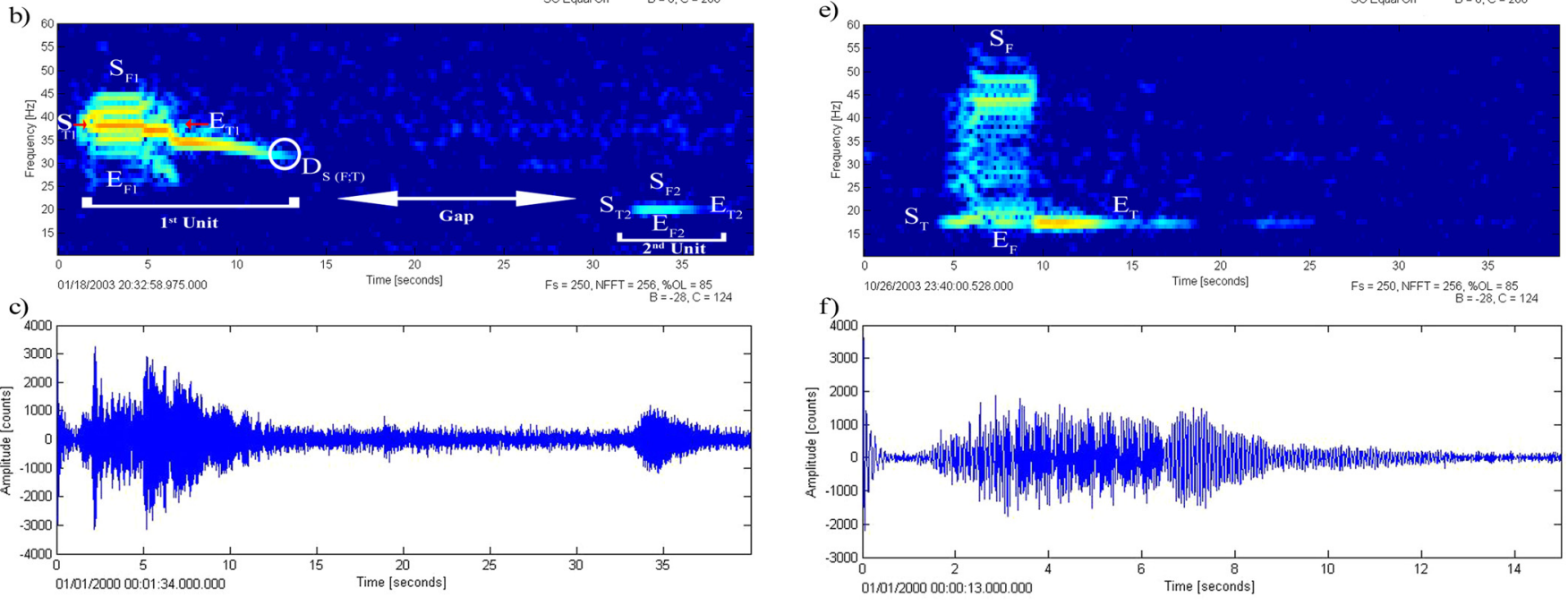

FIG. 2. (Color online) (a)-(c) Spectrograms of DGD signals. (a) Example of LTSA. (b) Spectrogram of DGD grade 1 signal with respective measurements. (c) Example of the signal waveform. (d)-(f) Spectrograms of DGC signals. (d) Example of LTSA. (e) Spectrogram of DGC signals grade 1 signal with respective measurements. (f) Example of the signal waveform. Spectrogram parameters: Frame size 250 samples, $85 \%$ overlap, Hanning window, equalized in (a) and (d); equalization off in (b) and (e). 
were selected with (2) limited background noise, (3) no overlapping signals, and (4) the selected signals had to be $24 \mathrm{~h}$ apart, to aid sample independence by increasing the probability that signals came from different sources. When several signals within a bout met these criteria, a single signal was randomly selected. Intercall interval was also measured using the two adjacent calls to the call selected for measurement, as long as these additional calls were determined to be part of the same calling bout and were also grade 1 calls.

To obtain accurate and consistent measurements, the spectrogram parameters were adjusted to the following: display length: $200 \mathrm{~s}$, Hanning window, plot frequency: 0-60 Hz, frame length: 512, samples overlap: $80 \%$, brightness: -4 , contrast: 200 , equalized [though equalization was also turned off to check that criteria (2) and (3) above were met]. Triton was used to take measurements of signal duration (start and end time), the frequency range (start and end frequency) and intercall interval of both signals (defined as the time gap from the end of one signal to the start of the next). For the DGD signal additional measures were taken, namely, the downsweep frequency and the interunit gap. The mean values with associated standard error [mean\pm standard error (s.e.)] are presented for all signal measurements.

Some detected DGD signals also had no second unit present despite having a high signal-to-noise ratio. These single-unit signals were classified as DGD signals and graded accordingly but were not measured and therefore are not represented in the signal's average measurements.

The number of days with detected signals and the grading classification were summarized by month to provide information on the seasonal occurrence of both signals. Data were corrected for availability by dividing the number of days with detected calls by the number of days available in each month. Although the visual analysis focused on DGD and DGC signals, other signals of interest were also identified. Even though these signals are not the focus of this paper they were noted for future analyses.

\section{RESULTS}

DGD signals were detected in $43.6 \%$ of available days at DGN and $86.3 \%$ days at DGS. DGC signals were detected in $18.4 \%$ of available days at DGN and $3.0 \%$ days at DGS. The occurrence of both signals in the same month was much more common at the northern site. At DGN, there were 4 months in 2002 (January, May, June, and December) and 8 months in 2003 (January, February, July, August, September, October, November, and December) when both signals were detected. In particular, in 9 days in December 2002, both signals were found occurring in several of the same $200 \mathrm{~s}$ time windows. At DGS, May 2002 and August 2003 were the only months where both signals were detected. DGD measurements were taken from 22 signals and 10 measurements were taken from DGC signals. Some DGD signals had a third component between the first and second components. This third component generally had a lower signal-to-noise ratio than the main two components so it was not possible to take accurate measurements. Evidence of this extra component was found in 13 of the 22 DGD signals measured; it occurred between 20 and $26 \mathrm{~Hz}$ and measured durations ranged between 0.6 and $2 \mathrm{~s}$.

\section{A. Signal measurements}

DGD consisted of two main components. The first component had a complex structure, initially the sound was amplitude-modulated (pulsed) but became a frequencymodulated downsweep. The second component was a short constant frequency tone. The maximum and minimum frequencies of the first component were $45.0 \pm 0.2 \mathrm{~Hz}$ and $26.4 \pm 0.2 \mathrm{~Hz}$, respectively (Table I). The duration of the first unit was $10.2 \pm 0.6 \mathrm{~s}$. The downsweep of the signal ended at $31.4 \pm 0.1 \mathrm{~Hz}$. The duration between measurements $S_{\mathrm{T} 1}$ and $E_{\mathrm{T} 1}$ [Fig. 2(b)] in the first component of DGD was $5.3 \pm 0.2 \mathrm{~s}$ and the gap between the components was $18.5 \pm 0.2 \mathrm{~s}$. The second component of the signal had a maximum frequency of $20.9 \pm 0.1 \mathrm{~Hz}$, a minimum frequency of $19.3 \pm 0.2 \mathrm{~Hz}$, and a duration of $6.4 \pm 0.4 \mathrm{~s}$. Overall, the total

TABLE I. Acoustic characteristics of DGD $(n=22)$ and DGC $(n=10)$. "Feature measured" are the measured elements in both signals. "Mean \pm s.e." is the mean of averages for measured calls and the standard error of averages for measured calls, respectively. "Min.-Max. range" is the minimum and maximum range of the measured calls.

\begin{tabular}{|c|c|c|c|c|}
\hline Signal & feature & Feature measure & Mean \pm s.e. & Min.-Max. range \\
\hline \multirow[t]{11}{*}{ DGD } & 1st Unit & Start frequency $\left(S_{\mathrm{F} 1}\right)$ & $45.0 \pm 0.2 \mathrm{~Hz}$ & $44-48 \mathrm{~Hz}$ \\
\hline & & End frequency $\left(E_{\mathrm{F} 1}\right)$ & $26.4 \pm 0.2 \mathrm{~Hz}$ & $24-28 \mathrm{~Hz}$ \\
\hline & & Duration $\left(E_{\mathrm{T} 1}-S_{\mathrm{T} 1}\right)$ & $5.3 \pm 0.2 \mathrm{~s}$ & $4-7 \mathrm{~s}$ \\
\hline & & Downsweep frequency $\left(D s_{(\mathrm{F})}\right)$ & $31.4 \pm 0.1 \mathrm{~Hz}$ & $31-33 \mathrm{~Hz}$ \\
\hline & & Duration $\left(D s_{(\mathrm{T})}-S_{\mathrm{T} 1}\right)$ & $10.2 \pm 0.6 \mathrm{~s}$ & $5-13 \mathrm{~s}$ \\
\hline & 2nd Unit & Start frequency $\left(S_{\mathrm{F} 2}\right)$ & $20.9 \pm 0.1 \mathrm{~Hz}$ & $19-22 \mathrm{~Hz}$ \\
\hline & & End frequency $\left(E_{\mathrm{F} 2}\right)$ & $19.3 \pm 0.2 \mathrm{~Hz}$ & $18-21 \mathrm{~Hz}$ \\
\hline & & Duration $\left(E_{\mathrm{T} 2}-S_{\mathrm{T} 2}\right)$ & $6.4 \pm 0.4 \mathrm{~s}$ & $5-10 \mathrm{~s}$ \\
\hline & 1st Unit +2 nd Unit & Interunit gap (1st-2nd unit) & $18.5 \pm 0.2 \mathrm{~s}$ & $16-20 \mathrm{~s}$ \\
\hline & & Overall duration $\left(E_{\mathrm{T} 2}-S_{\mathrm{T} 1}\right)$ & $36.5 \pm 0.4 \mathrm{~s}$ & $34-40 \mathrm{~s}$ \\
\hline & & Average intercall interval & $4.0 \pm 0.3 \mathrm{~m}$ & $1-8 \mathrm{~m}$ \\
\hline \multirow[t]{4}{*}{ DGC } & & Start frequency $\left(S_{\mathrm{F}}\right)$ & $49.6 \pm 0.6 \mathrm{~Hz}$ & $48-55 \mathrm{~Hz}$ \\
\hline & & End frequency $\left(E_{\mathrm{F}}\right)$ & $16.9 \pm 0.1 \mathrm{~Hz}$ & $16-17 \mathrm{~Hz}$ \\
\hline & & Duration $\left(S_{\mathrm{T}}-E_{\mathrm{T}}\right)$ & $13.1 \pm 0.6 \mathrm{~s}$ & $11-17 \mathrm{~s}$ \\
\hline & & Average intercall interval & $3.1 \pm 0.3 \mathrm{~m}$ & $2-5 \mathrm{~m}$ \\
\hline
\end{tabular}




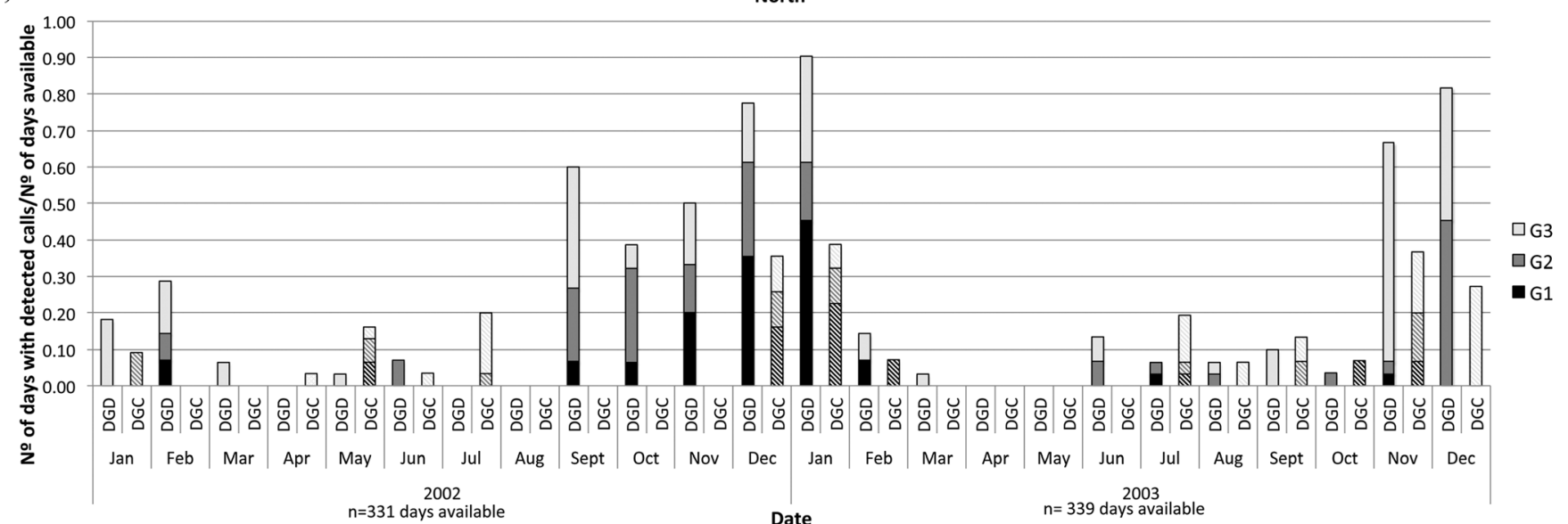

b)

South

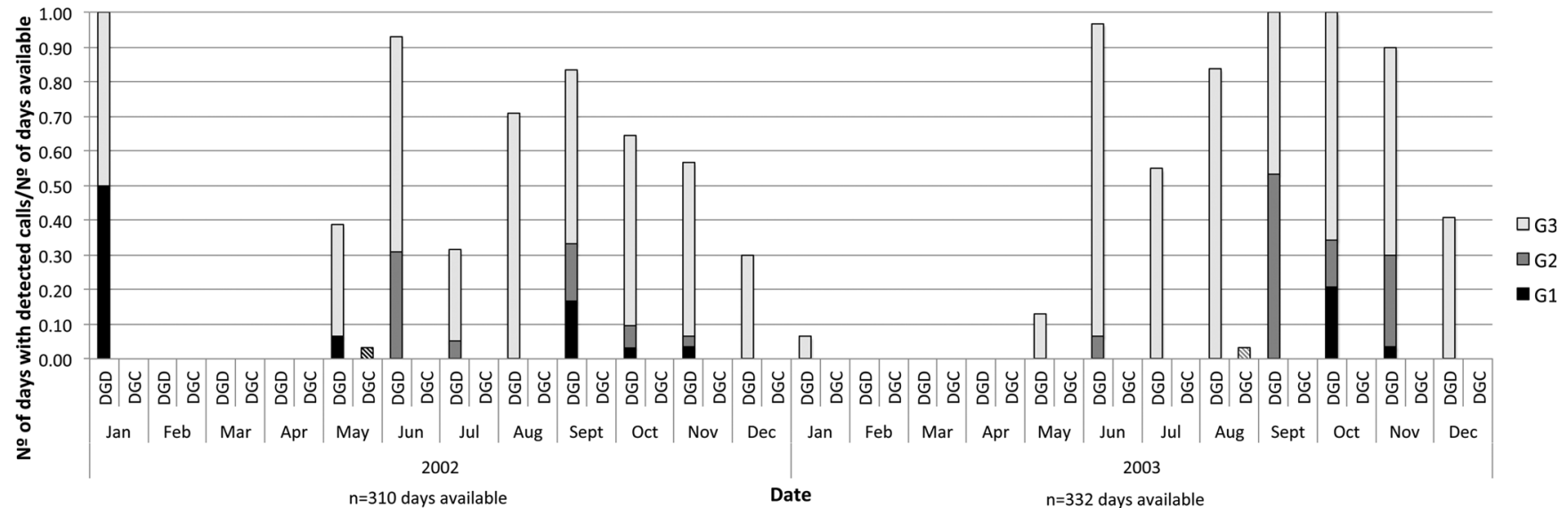

FIG. 3. Detections of DGD and DGC signals per month between January 2002 and December 2003 at (a) the northern (DGN) and (b) the southern (DGS) site, corrected for the number of days of available data. The quality of the detected signals in each month is summarized by showing the maximum signal grade detected per day $(G 1=$ grade $1, G 2=\operatorname{grade} 2$, and $G 3=$ grade 3$)$.

duration of the entire DGD signal was $36.5 \pm 0.4 \mathrm{~s}$. The average intercall interval was $4.0 \pm 0.3 \mathrm{~min}$ (based on 26 measurements from 14 signals).

The DGC signal consisted of one unit with a maximum frequency of $49.6 \pm 0.6 \mathrm{~Hz}$ and a minimum frequency of $16.9 \pm 0.1 \mathrm{~Hz}$ (Table I). The signal was initially amplitudemodulated but ended with a constant frequency tone. The duration of the signal was $13.1 \pm 0.6 \mathrm{~s}$ and the average intercall interval was $3.1 \pm 0.3 \mathrm{~min}$ (11 intercall interval measurements were taken from 8 signals).

\section{B. Signal seasonality}

The DGD signal was detected in most months at both sites. At DGN signals were generally detected most often from September to February, and less often from March to August (Fig. 3). At DGS, DGD signals were detected from May to January in both 2002 and 2003 with no signals detected in February, March, and April (Fig. 3). At DGN, January 2003 was the peak month for detections. At DGS, the month with the most days with detected DGD signals was September 2003. It should be noted that data were available for less than 28 days in January 2002, July 2002, and
December 2003 and results could therefore differ if data for the entire month were available.

At DGN, Grade 1 signals were detected in 5 months in 2002 and in 4 months in 2003. The highest proportion of grade 1 signals was found in January 2003 (Fig. 3). Grade 2 signals were found in 6 months in 2002 and in 8 months in 2003. Grade 3 signals were found in all months where signals were detected.

At DGS, grade 1 and grade 2 signals were more often detected in the months of June, September, October, and November. The majority of signals detected were grade 3 . The percentage of grade 1 and 2 signals at DGN was higher than the percentage observed at DGS, where grade 3 signals were prevalent.

Regarding DGC signals, there was a clear difference between the northern and southern sites in the number of days with signals detected. At DGN, signal detection peaked in December 2002, January 2003, and November 2003. In February and March 2002 and between August and November 2002, no signals were detected. In 2003, no signals were detected between March and June (Fig. 3). At DGN there was no clear difference in the proportion of differently graded signals. Grade 1 signals were detected in 2 months in 2002 and in 5 months in 2003. 
At DGS, grade 1 signals were detected in May 2002 and grades 2 and 3 in both months.

\section{Other signals of interest}

During this period several other biological signals were opportunistically detected. In June and July 2003 at DGN both fin whale calls and signals that resembled blue whale $D$ calls (Oleson et al., 2007a; Oleson et al., 2007b; Samaran et al., 2010) were detected.

\section{DISCUSSION}

\section{A. Detection method and grading system}

A visual detection method was used due to the complex structure and range of frequencies of both signals, which may have made the development of an automatic detector challenging. The main disadvantage of using a visual detection method is that it is labor intensive-in this analysis the dataset was too large to annotate every occurrence of either signal. In addition, single signals or short signal bouts may have been missed, though single grade 1 signals were visible in the LTSA. However, the main aim of this study was to describe the signals in detail and their broad seasonal patterns of occurrence, which did not require every signal to be logged. Furthermore, there were two main advantages to detecting signals visually. First, fainter signals were easily detected, whereas an automatic detector may have potentially only detected grade 1 signals. The detection of only the strongest signals may have then affected the observed seasonality pattern. For example, at the southern site, most detected DGD signals were grade 3 (Fig. 3).

Second, a visual detection method also allows for the opportunistic detection of other signals that would not be detected by a detector developed to find the main signals of interest. In this study, fin whale calls and suspected blue whale $D$ calls were detected. $D$ calls have been previously detected in the southern Indian Ocean (Samaran et al., 2010). An extension of this study would be to measure the time and frequency parameters of these two call types and document their seasonal patterns of occurrence.

\section{B. DGD and DGC are suspected whale calls}

There are many sources of low frequency sounds in the ocean. These sounds can be broadly categorized as being caused by biological (e.g., whales), anthropogenic (e.g., shipping), or physical processes (e.g., earthquakes). Stafford et al. (1999) established a set of criteria to identify potential biological signals. In summary, two temporal criteria were defined: signals that displayed (1) non-random patterns of production and/or (2) seasonal patterns of detection were considered likely to be produced by a biological source. Frequency characteristics were also considered as criteria; signals that were non-continuous and narrowband (relative to the entire frequency spectrum), contained frequency- or amplitude-modulation and had frequencies higher than $10 \mathrm{~Hz}$ were also considered to be of biological origin. Variation within signal types (i.e., single-component DGD signals) may also be further evidence of a biological source.
Both DGD and DGC signals meet these criteria and are suspected to be produced by large whales due to the low frequency range of both signals and similarities with other baleen whale vocalizations (discussed further below). However, other biological sources should not be completely discounted; fish also make low frequency sounds below 2 $\mathrm{kHz}$, for example (Mann et al., 2008). Six baleen whale species are known to occur in the Indian Ocean Sanctuary (IOS; area shown in Fig. 1); Bryde's whales (B. edeni), humpback whales (Megaptera novaengliae), minke whales $(B$. acutorostrata), blue whales (B. musculus), sei whales (B. borealis), and fin whales (B. physalus) (de Boer et al., 2003). All of these species are known to produce vocalizations (Mellinger et al., 2007), though calls from only blue, fin, and humpback whales have been definitively identified and reported in the Indian Ocean (fin whales, this study; humpback whales, e.g., Murray et al., 2012; blue whales, e.g., Stafford et al., 2004). All six species are known to produce more than one type of vocalization and display intraspecific geographical variation in their repertoires, which may be an acoustic indicator of separate populations (Helweg et al., 1998; Mellinger and Barlow, 2003; McDonald et al., 2006; Delarue et al., 2009; Gedamke, 2009).

Baleen whale calls also show variation within specific call types. For example, there are frequency differences in the high frequency component of fin whale calls (Širović et al., 2009). If DGD signals are baleen whale calls, then the occurrence of the DGD single-component calls could be due to such call type variation. However, visual differences between signals may not always be due to true signal type variability. In this study, the absence of the third component in some DGD signals may be caused by its low signal-tonoise ratio, rather than lack of production.

The described signals could be additional call types of previously recorded species, or the first recordings of Indian Ocean minke, sei, or Bryde's whales. Furthermore, the vocalizations of mysticetes can be classified into two categories-calls and songs. Songs are defined as "sequences of notes occurring in a regular sequence and patterned in time" (Clark, 1990, cited in Au and Hastings, 2008). To date, five species of mysticete are known to produce song — humpback whales, blue whales, fin whales, minke whales, and bowhead whales (Balaena mysticetus) (Janik, 2009). Both signals were observed in long bouts that could last many hours, had seasonal patterns, and low intercall interval variability, indicating that these signals could potentially be examples of the baleen whale song. The remainder of this section discusses how likely it is that each of the baleen whale species occurring in the IOS could be a source of the DGD and DGC signals, given what is known about existing vocalizations.

Across other oceans, minke whales are known to produce a range of sounds including pulses, clicks, downsweeps, and a variety of other frequency-modulated sounds (e.g., boing, "star wars," and "bio-duck" signals) (e.g., Beamish and Mitchell, 1973; Edds-Walton, 2000; Mellinger et al., 2000; Gedamke et al., 2001; Rankin and Barlow, 2005; Oswald et al., 2011; Risch et al., 2013; Risch et al., 2014). It has been suggested that pulses, the star-wars signals, and boings may act as song. All of these call types are 
relatively low frequency, though the majority of energy in all of these signal types occurred above $50 \mathrm{~Hz}$ and frequencies of clicks, harmonics of the star wars signal, and the fundamental frequency of boings exceed $1 \mathrm{kHz}$. Therefore, the frequencies of the DGD and DGC signals are uncharacteristically low compared to other minke whale calls, unless there are higher frequencies in the signals that cannot be detected by the CTBTO hydrophones.

The two other baleen whale species whose vocalizations have not yet been recorded in the IOS are Bryde's whales and sei whales. Furthermore, to date, calls from these species have not been presented as a suspected song. A variety of Bryde's whale calls have been recorded in the Pacific and Atlantic Oceans (summarized in Oleson et al., 2003). All sounds contained frequencies less than $1 \mathrm{kHz}$ and, in particular, six of the nine call types reported by Oleson et al. (2003) did not contain frequencies above $50 \mathrm{~Hz}$. These six lowest frequency call types had mean durations of less than $3 \mathrm{~s}$, which is considerably shorter than both unidentified signals reported here. Similarly, several different sei whale calls have been described (summarized in Baumgartner et al., 2008). Some reported sei whale calls exceeded $1 \mathrm{kHz}$, but Rankin and Barlow (2007) described a low frequency downsweep that did not exceed $50 \mathrm{~Hz}$. Although in a similar frequency range to the unidentified signals, the downsweeps had a simple tonal structure and were less than $1.5 \mathrm{~s}$ in duration. Downsweeps are also produced by known songproducing species such as minke, blue, and fin whales so, although the unidentified signals have very different time characteristics to known calls of these species, it is possible that the unidentified signals could be attributed to sei or Bryde's whale song.

Of the previously recorded species in the Indian Ocean, we suggest that the signals are more similar to other blue whale song types, than humpback or fin whale song. The main component of the fin whale song appears to be the "20 Hz pulse" (e.g., Širović et al., 2009; Watkins et al., 1987), which has been described in different oceans and is the call type seen in this dataset. The humpback song has a complex hierarchical structure, comprised of more than one type of call and typically includes frequencies greater than 1 $\mathrm{kHz}$ (Payne and McVay, 1971; Murray et al., 2012). The low sampling rate of the CTBT hydrophones means that it was not possible to check whether the signals had a higher frequency content above $125 \mathrm{~Hz}$, but the absence of energy above $55 \mathrm{~Hz}$ in any of the measured signals (of either type) suggests that it is unlikely that these signals contained higher frequencies.

The duration of the signals appears to be more similar to other blue whale call types (e.g., McDonald et al., 2006) than the other considered call or song types. Therefore, based on the time and frequency characteristics, and current knowledge of the vocalizations of other species, these signals appear to be most similar to other blue whale calls types and, further, could be new examples of a blue whale song.

To date, four main different types of calls recorded in the IOS have been attributed to blue whales and categorized as song (McDonald et al., 2006). Labelled in the literature by the geographic area in which they have been recorded most often, they are known as Antarctic, Madagascan, Sri Lankan, and Australian calls (Samaran et al., 2013). The Antarctic call has been attributed to Antarctic blue whales, while the Madagascan, Sri Lankan, and Australian calls have been attributed to pygmy blue whales (Ljungblad et al., 1998; McCauley et al., 2001).

The Antarctic blue whale call consists of three tonal units and its frequency ranges from 28 to $18 \mathrm{~Hz}$ with a duration of $\sim 26 \mathrm{~s}$ and repeated every 40-50s (Samaran et al., 2013). The Australian call consists of a three unit phrase with the first unit ranging from 19 to $21 \mathrm{~Hz}$ and with an overall duration of $43 \mathrm{~s}$. The second unit consisted of $23 \mathrm{~s}$ duration with a $20-26 \mathrm{~Hz}$ frequency range. The last part is a near constant frequency $18-19 \mathrm{~Hz}$ tone that lasts $26-48 \mathrm{~s}$ and follows the second unit by $23 \mathrm{~s}$ (Stafford et al., 2011). Sri Lankan calls are composed of three unit phrases ranging from 20 to $108 \mathrm{~Hz}$ with duration of $\sim 62 \mathrm{~min}$. Phrases are repeated every 70-80 s (Samaran et al., 2013).

The intercall intervals of the Australian and Madagascan calls are the most similar to DGD and DGC, given that the repetition rate of both signals was in the order of minutes (Samaran et al., 2013). The Antarctic and Sri Lankan blue whales call sequences display an intercall interval from 40 to $50 \mathrm{~s}$ and from 70 to $80 \mathrm{~s}$, respectively (Samaran et al., 2013).

The DGD signal has been previously described as the Diego Garcia variant of the Madagascan blue whale call type (McDonald et al., 2006). However, we suggest that DGD ought to be considered as a separate call type (possibly produced by another species), as it is very distinct from the Madagascan call. The DGD frequency range is from $\sim 19$ to $45 \mathrm{~Hz}$ with an overall duration of $\sim 36.5 \mathrm{~s}$ and average intercall interval of $4 \mathrm{~min}$. The main energy of the Madagascan call, as reported by Ljungblad et al. (1998), ranges from 38 to $15 \mathrm{~Hz}$ and the call is repeated approximately every 90-100 s (Ljungblad et al., 1998).

In contrast, the DGC signal has not been previously described or attributed to any particular whale species.

\section{Seasonality pattern}

When interpreting seasonality patterns, there are a number of factors to consider. First, although DGD and DGC signals were detected on the hydrophones at Diego Garcia, it is possible that they were produced at substantial distances from the hydrophones, given that the instruments were moored in the SOFAR channel. In addition, if these signals are baleen whale calls, the signals' potential source levels could be high. For example, the average source levels of blue and fin whales in the Antarctic were estimated to be $189 \mathrm{~dB}$ re.1 $1 \mu \mathrm{Pa} @ 1 \mathrm{~m}$ (Širović et al., 2007). Further work would be needed to estimate the detection range of both unidentified signals around the Diego Garcia hydrophones. Detection range is not only highly dependent on the characteristics of the signal of interest and bottom topography of the monitored area but is also dependent on oceanographic variables that alter seasonally, which could influence the patterns of the signals' occurrence (Lurton, 2002). The occurrence of different grades of signals may be evidence that 
signals are originating from different ranges, that they are being affected by varying oceanography, or that the source levels of the signals are variable.

Second, it is not clear whether the same signals detected at the northern site (DGN) could also be detected in the southern site (DGS) and vice versa. It has been predicted that the hydrophones at Diego Garcia suffer from hydroacoustic blockage because the island can block signals from certain directions. A simulation exercise (Pulli and Upton, 2001) predicted blockage east of the northern site and northwest of the southern site. However, although simulations suggested that, in some cases, the same signal should not be received at both sites, Pulli and Upton (2001) found that seismic signals were detected at both sites. Therefore, the patterns of the signals' occurrence at both sites may not be independent. The fact that the same signals could be simultaneously contributing to the patterns at both sites should be taken into consideration when interpreting the site-specific differences, especially in terms of possible animal migration between sites. Finally, if these signals are songs produced by whales, it must be considered that despite "calling" activity appearing to be high due to the number of days containing signals, calling may be due to relatively few animals.

The DGD signal in the northern site shows a peak in the austral summer whilst in the southern site the peak spans from winter through spring. If DGD signals are whale calls, it is not known if animals move out of the Diego Garcia area when detections of DGD decrease, or if animals are present but not calling, or if calls are produced but become more difficult to detect. It may be that animals move to the southern site during the austral winter since this peak in the southern site coincides with a reduction in the number of days with DGD detections in the northern site. Similarly, animals may move further north during the summer to be primarily detected at the northern site. The seasonality pattern of DGC at the northern site has a peak in the austral summer in both years but also in the austral winter during 2002. In the southern site signals were only detected on two days, one in March 2002 and another in August 2003. The reason for this pattern is unclear though it is possible that, if these signals are whale calls, the animals that produce this call may be distributed further north, not moving to the southern area or are migrating pass the hydrophone (Thompson and Friedl, 1982) and therefore not recorded in our data, except occasionally.

Knowledge of blue whale migration patterns in the IOS are not clearly understood (Samaran et al., 2013; Stafford et al., 2011). Antarctic blue whales are thought to migrate to Antarctica in the austral summer to feed and return to lower latitudes in the austral winter to breed (Samaran et al., 2013). However, a low number of calls were detected in February-April in the south coast of Australia suggesting some Antarctic blue whale individuals may not migrate to feeding grounds (Tripovich et al., 2015). Australian pygmy blue whales are thought to migrate to Indonesia in the summer to breed and return to Australia in the winter to feed (Double et al., 2014). The Madagascan pygmy blue whales migrate south of Madagascan from late summer through winter to feeding grounds and return to higher latitudes in the end of autumn. Madagascan calls have been detected at the Crozet archipelago from January to June and in May and June further north at Diego Garcia. The differences in seasonal detections may indicate the prevalence of a population that primarily occupies the western Indian and Southern Oceans with some individuals occasionally moving northwards by the end of autumn (Stafford et al., 2011).

Various studies have discussed the link between blue whale recordings and migration patterns in the Indian Ocean. Of the calls recorded on the Diego Garcia hydrophones, Sri Lankan blue whale calls are the most frequently observed blue whale call type (Stafford et al., 2004; Stafford et al., 2011; Harris, 2012; Samaran et al., 2013). The detection peaks in Sri Lanka calls at the northern site showed an increase in the austral winter and a decrease in the austral summer (Stafford et al., 2011; Harris, 2012). Detections of Sri Lanka calls at the southern site showed a bimodal annual pattern, increasing in the austral summer and winter (Stafford et al., 2011; Harris, 2012). Sri Lankan calls have, to date, primarily been detected year round in the northern Indian Ocean suggesting that the whales making these calls may not migrate to the Antarctic (Samaran et al., 2013). In addition, it has been hypothesised that most whales in the northern Indian Ocean would move north to the Arabic Sea during periods of intense upwelling to feed (Anderson et al., 2012). The seasonality pattern of the Sri Lankan call seems to present a pattern opposite to the DGD signal at the northern site. If the DGD signal is also made by a blue whale, then this could be interpreted in two ways: either separate groups of animals could be making the Sri Lankan calls and the DGD signal but are using the same area around Diego Garcia in varying ways, or the same animals are making both signals, which have two different functions and are therefore used by the animals at varying times.

Acoustic detections of the Madagascan blue whale in the Diego Garcia dataset were only recorded in the northern site in May, June, and July 2002 and in July 2003 (Stafford et al., 2011). The seasonality pattern of DGD signals is not comparable to the Madagascan blue whale call, supporting our suggestion that these two signals should be considered as separate call types. Antarctic blue whale calls have also been recorded at both the northern and southern sites; peak detections occurred between May and July at both sites (Stafford et al., 2004), suggesting that either the CTBTO hydrophones have a large monitoring radius, or that blue whales are undertaking considerable migrations between the Southern Ocean and the northern Indian Ocean, or both.

\section{CONCLUSIONS}

The two signals described in this study have not been described in detail elsewhere in the literature. In general, blue whales produce stereotyped calls consisting of several units with high intensity, lower frequency, and longer durations consistent with the two signals described in this study. Further investigation of these signals by screening of other Indian Ocean datasets may help to identify their source and support the evidence stated that these are possible blue whale calls. 


\section{ACKNOWLEDGMENTS}

The data were collected by the Comprehensive Test Ban Treaty Organization as part of their IMS. Part of the data analysis was conducted as part of D.H.'s Ph.D. thesis, which was funded by the UK Defence Science Technology Laboratory, Grant No. RD034-014166. We are very grateful to two anonymous reviewers, whose comments have substantially improved this manuscript.

Anderson, C., Branch, T. A., Alagiyawadu, A., Baldwin, R., and Marsac, F. (2012). "Seasonal distribution, movements and taxonomic status of blue whales (Balaenoptera musculus) in the northern Indian Ocean," J. Cetacean Res. Mgmt. 12(2), 203-218.

$\mathrm{Au}$, W. W. L., and Hastings, M. C. (2008). Principles of Marine Bioacoustics. Modern Acoustics and Signal Processing (Springer-Verlag, New York), 679 pp.

Baumgartner, M. F., van Parijs, S. M., Wenzel, F. W., Tremblay, C. J., Esch, H. C., and Warde, A. M. (2008). "Low frequency vocalizations attributed to sei whales (Balaenoptera borealis)," J. Acoust. Soc. Am. 124(2), 1339-1349.

Beamish, P., and Mitchell, E. (1973). "Short pulse length audio frequency sounds recorded in the presence of a minke whale (Balaenoptera acutorostrata)," Deep-Sea Res. Oceanogr. Abstr. 20, 375-386.

Burton, J. A., and Nietsch, A. (2010). "Geographical variation in duet songs of Sulawesi Tarsiers: Evidence for new cryptic species in south and southeast Sulawesi,” Int. J. Primatol. 31, 1123-1146.

Celis-Murillo, A., Deppe, J. L., and Allen, M. F. (2009). "Using soundscape recordings to estimate bird species abundance, richness, and composition," J. Field Ornithology 80(1), 64-78.

Clark, C. W. (1990). "Acoustic behavior of mysticete whales," in Sensory Abilities of Cetaceans, edited by J. A. Thomas and R. A. Kastelein (Plenum, New York), pp. 571-583.

de Boer, M. N., Baldwin, R., Burton, C. L. K., Eyre, E. L., Jenners, K. C. S., Jenners, M.-N. M., Keith, S. G., McCabe, K. A., Parsons, E. C. M., Peddemors, V. M., Rosenbaum, H. C., Rudolph, P., and Simmonds, M. P. (2003). "Cetaceans in the Indian Ocean: A review," WDCS Science Report, $52 \mathrm{pp}$.

Delarue, J., Todd, S. K., Van Parijs, S. M., and Di Iorio, L. (2009). "Geographic variation in Northwest Atlantic fin whale (Balaenoptera physalus) song: Implications for stock structure assessment," J. Acoust. Soc. Am. 125(3), 1774-1782.

Double, M. C., Andrews-Goff, V., Jenner, K. C. S., Jenner, M.-N., Laverick, S. M., Branch, T. A., and Gales, N. J. (2014). "Migratory movements of pygmy blue whales (Balaenoptera musculus brevicauda) between Australia and Indonesia as revealed by satellite telemetry," PLoS ONE 9(4), e93578.

Edds-Walton, P. L. (2000). "Vocalizations of minke whales Balaenoptera acutorostrata in the St. Lawrence Estuary,” Bioacoustics 11, 31-50.

Gedamke, J. (2009). "Geographic Variation in Southern Ocean Fin Whale Song," International Whaling Commission report SC/61/SH16, pp. 1-8.

Gedamke, J., Costa, D., and Dunstan, A. (2001). "Localization and visual verification of a complex minke whale vocalization," J. Acoust. Soc. Am. 109, 3038-3047.

Hanson, J. A. (2001). "Initial analysis of data from the new Diego Garcia hydroacoustic station," in Proceedings of the 23rd Seismic Research Review, Vol. II, pp. 12-22.

Harris, D. (2012). "Estimating whale abundance from sparse hydrophone arrays," Ph.D. thesis, University of St Andrews.

Helweg, D. A., Cato, D. H., Jenkins, P. F., Garrigue, C., and McCauley, R. D. (1998). "Geographic variation in South Pacific humpback whale songs," Behaviour 135, 1-27.

Hu, W., Bulusu, N., Chou, C. T., Jha, S., Taylor, A., and Tran, V. N. (2009). "Design and evaluation of a hybrid sensor network for cane toad monitoring," ACM Trans. Sensor Networks 5(1), 1-30.

Janik, V. (2009). "Whale song," Curr. Biol. 19(3), 109-111.

Ljungblad, D. K., Clark, C. W., and Shimada, H. (1998). "A comparison of sounds attributed to pygmy blue whales (Balaenoptera musculus brevicauda) recorded south of the Madagascar Plateau and those attributed to 'true' blue whales (Balaenoptera musculus) recorded off Antarctica," Rpt. Int. Whaling Comm. 48, 439-442.
Luczkovich, J. J., Mann, D. A., and Rountree, R. A. (2008). "Passive acoustics as a tool in fisheries science," Trans. Am. Fish. Soc. 137, 533-541.

Lurton, X. (2002). An Introduction to Underwater Acoustics: Principles and Applications (Praxis Publishing Ltd., Chichester, UK), 347 pp.

Mann, D. A., Hawkins, A. D., and Jech, M. J. (2008). "Active and passive acoustics to locate and study fish," in Fish Bioacoustics, edited by J. F. Webb, R. R. Fay, and A. Popper (Springer, New York), pp. 279-309.

Mathworks (2012). The Mathworks, Inc., Cambridge, U.K. http:// www.mathworks.co.uk (Last viewed January 25, 2012).

McCauley, R. D., Jenner, C., Bannister, J. L., Burton, C. L. K., Cato, D. H., and Duncan, A. (2001). "Blue whale calling in the Rottnest Trench2000, Western Australia," Report R2001-6, Centre for Marine Science and Technology, Curtin University of Technology, Perth, Western Australia, $55 \mathrm{pp}$.

McDonald, M. A., Mesnick, S. L., and Hildebrand, J. A. (2006). "Biogeographic characterisation of blue whale song worldwide: Using song to identify populations," J. Cetacean Res. Mgmt. 8(1), 55-65.

Mellinger, D. K., and Barlow, J. (2003). "Future directions for marine mammal acoustic surveys: Stock assessment and habitat use," Report of a workshop held in La Jolla, CA, November 20-22, 2002. Technical contribution No. 2557, NOAA Pacific Marine Environmental Laboratory, Seattle, WA, 45 pp.

Mellinger, D., Carson, C., and Clark, C. (2000). "Characteristics of minke whale (Balaenoptera acutorostrata) pulse trains recorded near Puerto Rico,” Mar. Mammal Sci. 16(4), 739-756.

Mellinger, D., Stafford K. M., Moore, S. E., Dziak, R. P., and Matsumoto, H. (2007). "An overview of fixed passive acoustic observation methods for cetaceans," Oceanography 20, 36-45.

Murray, A., Cerchio, S., McCauley, R., Jenner, C. S., Razafindrakoto, Y., Coughran, D., McKay, S., and Rosenbaum, H. (2012). "Minimal similarity in songs suggests limited exchange between humpback whales (Megaptera novaeangliae) in the southern Indian Ocean," Mar. Mammal Sci. 28, E41-E57.

Oleson, E. M., Barlow, J., Gordon, J., Rankin, S., and Hildebrand, J. A. (2003). "Low frequency calls of Bryde's whales," Mar. Mammal Sci. 19(2), 407-419.

Oleson, E. M., Calambokidis, J., Burgess, W. C., McDonald, M. A., LeDuc, C. A., and Hildebrand, J. A. (2007a). "Behavioral context of call production by eastern North Pacific blue whales," Mar. Ecol. Prog. Ser. 330, 269-284.

Oleson, E. M., Wiggins, S. M., and Hildebrand, J. A. (2007b). "Temporal separation of blue whale call types on a southern California feeding ground," Anim. Behav. 74, 881-894.

Oswald, J. N., Au, W. W. L., and Duennebier, F. (2011). "Minke whale (Balaenoptera acutorostrata) boings detected at the Station ALOHA Cabled Observatory," J. Acoust. Soc. Am. 129, 3353-3360.

Payne, R. S., and McVay, S. (1971). "Songs of humpback whales," Science 173, 585-597.

Preparatory Commission for the Comprehensive Nuclear-Test-Ban Treaty Organisation (CTBTO). (2010). Vienna International Centre, Austria $<$ http://www.ctbto.org $>$ (Last viewed January 25, 2012).

Puissant, S., and Sueur, J. (2010). "A hotspot for Mediterranean cicadas (Insecta: Hemiptera: Cicadidae): New genera, species and songs from southern Spain," Syst. Biodivers. 8(4), 555-574.

Pulli, J. J., and Upton, Z. M. (2001). "Hydroacoustic blockage at Diego Garcia: Models and observations," in 23rd Seismic Research Review, Wyoming (October 2-5), pp. 45-54.

Rankin, S., and Barlow, J. (2005). "Source of the North Pacific 'boing' sound attributed to minke whales," J. Acoust. Soc. Am. 118(5), 3346-3351.

Rankin, S., and Barlow, J. (2007). "Vocalizations of the sei whale Balaenoptera borealis off the Hawaiian Islands," Bioacoustics 16, 137-145.

Risch, D., Clark, C. W., Dugan, P. J., Popescu, M., Siebert, U., and Van Parijs, S. (2013). "Minke whale acoustic behavior and multi-year seasonal and diel vocalization patterns in Massachusetts Bay, USA," Mar. Ecol. Prog. Ser. 489, 279-295.

Risch, D., Gales, N. J., Gedamke, J., Kindermann, L., Nowacek, D. P., Read, A. J., Siebert, U., Van Opzeeland, I. C., Van Parijs, S. M., and Friedlaender, A. S. (2014). "Mysterious bio-duck sound attributed to the Antarctic minke whale (Balaenoptera bonaerensis)," Biol. Lett. 10(4), 20140175.

Rojas-Bracho, L., Jaramillo-Legorreta, A. M., Taylor, B., Barlow, J., Gerrodette, T., Tregenza, N., Swift, R., and Akamatsu, T. (2010). 
"Assessing trends in abundance for vaquita using acoustic monitoring: Within refuge plan and outside refuge research needs," Paper SC/62/SM5 presented to the IWC Scientific Committee (Agadir, Morocco, June 2010), 11 pp.

Samaran, F., Adam, O., and Guinet, C. (2010). "Discovery of a mid-latitude sympatric area for two Southern Hemisphere blue whale subspecies," Endanger. Spec. Res. 12, 157-165.

Samaran, F., Stafford, K. M., Branch, T. A., Gedamke, J., Royer, J.-Y., Dziak, R. P., and Guinet, C. (2013). "Seasonal and geographic variation of southern blue whale subspecies in the Indian Ocean," PLoS ONE 8(8), e71561.

Širović, A., Hildebrand, J. A., and Wiggins, S. M. (2007). "Blue and fin whale call source levels and propagation range in the Southern Ocean," J. Acoust. Soc. Am. 122(2), 1208-1215.

Širović, A., Hildebrand, J. A., Wiggins, S. M., and Thiele, D. (2009). "Blue and fin whale acoustic presence around Antarctica during 2003 and 2004," Mar. Mamm. Sci. 25(1), 125-136

Stafford, K. M., Bohnenstiehl, D. R., Tolstoy, M., Chapp, E., Mellinger, D. K., and Moore, S. E. (2004). "Antarctic-type blue whale calls recorded at low latitudes in the Indian and eastern Pacific Oceans," Deep Sea Res., Part I 51, 1337-1346.

Stafford, K. M., Chapp, E., Bohnenstiel, D. R., and Tolstoy, M. (2011). "Seasonal detection of three types of 'pygmy' blue whale calls in the Indian Ocean," Mar. Mammal Sci. 27, 828-840.

Stafford, K. M., Mellinger, D. K., Moore, S. E., and Fox, C. G. (2007). "Seasonal variability and detection range modelling of baleen whale calls in the Gulf of Alaska, 1999-2002," J. Acoust. Soc. Am. 122(6), 3378-3390.

Stafford, K. M., Nieukirk, S. L., and Fox, C. G. (1999). "Low-frequency whale sounds recorded on hydrophones moored in the eastern tropical Pacific," J. Acoust. Soc. Am. 106(6), 3687-3698.
Thompson, P. O., and Friedl, W. A. (1982). "A long term study of low frequency sounds from several species of whales off Oahu, Hawaii," Cetology 45, 1-19.

Tripovich, J. S., Klinck, H., Nieukirk, S. L., Adams, T., Mellinger, D. K., Balcazar, N. E., Klinck, K., Hall, E. J. S., and Rogers, T. L. (2015). "Temporal segregation of the Australian and Antarctic blue whale call types (Balaenoptera musculus spp.)," J. Mammal. 96, 603-610.

Tyack, P. L., Johnson, M., Aguilar Soto, N., Sturlese, A., and Madsen, P. T. (2006). "Extreme diving of beaked whales," J. Exp. Biol. 209, 4238-4253.

U.S. Army Space and Missile Defence Command Monitoring Research Program $<$ www.rdss.info $>$ (Last viewed January 25, 2012).

Van Opzeeland, I., Van Parijs, S., Bornemann, H., Frickenhaus, S., Kindermann, L., Klinck, H., Plötz, J., and Boebel, O. (2010). "Acoustic ecology of Antarctic pinnipeds," Mar. Ecol. Prog. Ser. 414, 267-291.

Watkins, W. A., Daher, M. A., George, J. E., and Rodriguez, D. (2004). "Twelve years of tracking $52-\mathrm{Hz}$ whale calls from a unique source in the North Pacific," Deep Sea Res., Part I 51, 1889-1901.

Watkins, W. A., George, J. E., Daher, M. A., Mullin, K., Martin, D. L., Haga, S. H., and DiMarzio, N. A. (2000). "Whale call data for the North Pacific November 1995 through July 1999: Occurrence of calling whales and source locations from SOSUS and other acoustic systems," Technical Report No. WHOI-00-02, Woods Hole Oceanographic Institution, Woods Hole, MA, $160 \mathrm{pp}$.

Watkins, W. A., Tyack, P., Moore, K. E., and Bird, J. E. (1987). "The 20-Hz signals of finback whales (Balaenoptera physalus)," J. Acoust. Soc. Am. 82, 1901-1912.

Wiggins, S. M. (2003). "Autonomous Acoustic Recording Package (ARP's) for long term monitoring of whale sounds," Mar. Tech. Soc. J. 37, 13-22. 